\title{
PREVALENCE OF PHYSICAL, VERBAL AND NONVERBAL SEXUAL HARASSMENTS AND THEIR ASSOCIATION WITH PSYCHOLOGICAL DISTRESS AMONG JIMMA UNIVERSITY FEMALE STUDENTS: A CROSS-SECTIONAL STUDY
}

\author{
Almaz Mamaru ${ }^{1}$, Kinde Getachew ${ }^{1}$, Yasmin Mohammed ${ }^{1}$
}

\section{ABSTRACT}

BACKGROUND: A number of studies conducted on sexual harassment focused on general magnitude rather than specific details of the various forms of sexual harassment and their effect on psychological health. Thus, the objective of this study was to assess the prevalence rates of the various forms of sexual harassments and their associations with psychological distress among Jimma University female students.

METHODS: Three hundred and eighty five (385) female participants were selected from all colleges using stratified and systematic sampling techniques. A structured questionnaire consisting of items on the various forms of sexual harassment and psychological distress was administered.

RESULT: The prevalence rates of physical, verbal and nonverbal sexual harassments were $78.2 \%$, $\mathbf{9 0 . 4 \%}$ and $\mathbf{8 0 . 0 \%}$, respectively, while the prevalence rate of psychological distress among students who had experienced sexual harassment was 63.0\%. The multivariable logistic regression analyses indicated that students who were physically [adjusted $O R=3.950,95 \% C I=(1.979,7.884)]$ and nonverbally [(adjusted $O R=12.099,95 \% C I=(5.190,28.205]$ harassed were 4 and 12 times more likely to experience psychological distress, respectively, adjusted for all other variables.

CONCLUSION: The prevalence of various forms of sexual harassment were higher and strongly associated with psychological distress. Important implications for University officials and policy makers including creating harassment free University have been drawn. Otherwise, female students tend to dropout and their academic achievements suffer a lot as a result of psychological distress; and the government's effort for realizing the gender parity in education would be compromised.

KEYWORDS: Verbal sexual harassment, Nonverbal sexual harassment, Physical sexual harassment, Psychological distress

\section{DOI: http://dx.doi.org/10.4314/ejhs.v25i1.5}

\section{INTRODUCTION}

Despite the lack of a single meaning, sexual harassment is commonly defined as unwanted and unwelcome sexual behavior in a work or educational setting affecting both physical and psychological well-being of a person. It could be evident in three different ways: verbal, physical and nonverbal forms (1).
A number of studies indicated that sexual harassment against women is the most common problem globally and locally. A WHO report pointed out the problem has increased over the past 25 years impacting on women's physical and psychological well-being profoundly in all settings (2). However, sexual harassment is much more common in educational settings. A survey study in a school in America revealed that more than $80 \%$

\footnotetext{
${ }^{1}$ Department of Psychology, College of Education and Behavioral Sciences, Jimma University, Ethiopia Corresponding Author: Almaz Mamaru, Email: aem.alma@gmail.com
} 
of female students had experienced sexual harassment at least once in their school life, and also more than one-third of college female students had been victims of sexual harassment when they were first year students $(1,3,4)$.

With respect to the prevalence of sexual harassment in Ethiopian Universities, 35\%, 41.8\% and $42 \%$ of Bahirdar, Addis Ababa, and Jimma Universities' female students, respectively, reported that they had experienced sexual harassment $(5,6$, and 7). Similarly, a recent study conducted at Jimma University showed that $83 \%$ of female students were victims of sexual harassment (8).

Sexual harassment resulted in an enormous physical and psychological harm on women's lives (9). In line with this, a study conducted in Ebonyi State University of Nigeria disclosed that $89.8 \%$ of female students experienced psychosocial distress, and $56.5 \%$ reported that their academic achievements suffered a lot (10).

There are few local studies, to the researchers' knowledge, that documented the relationship of sexual harassment and female university students' psychological distress in the Ethiopian context. A study carried out at Bahirdar University showed that $93.6 \%$ of victims of sexual harassment did not share the incidents for anybody which undoubtedly worsened their psychological well-being (5).

A number of studies conducted worldwide and locally on sexual harassment usually focused on the prevalence of sexual harassment in general. They failed to address specifically the prevalence rates of physical, verbal and nonverbal harassments and their association with psychological health. Conceiving sexual harassment as containing one construct is not informative as the data might not make good sense; moreover, the extent of the various forms of sexual harassments should be investigated as they could call for different intervention strategies (3). Thus, this research attempted to fill the gaps pertaining to the prevalence of the various forms of sexual harassments and their association with psychological distress. The objective of the study was to investigate the prevalence of physical, verbal and nonverbal sexual harassments and their association with psychological distress among Jimma University female students.

\section{METHODS AND MATERIALS}

A cross-sectional institution-based study design was conducted among Jimma University female students from March to April, 2014. A single population proportion formula, assuming 35\% prevalence $(\mathrm{p})$ rate of sexual harassment which was secured from a recent study among Bahirdar University undergraduate female students (5), maximum discrepancy (d) of $\pm 5 \%$, and $95 \%$ certainty (confidence interval), was used to determine the sample size. Adding 10\% nonresponse rate, the final sample size was 385 female students. The sample size was proportionally allocated to each college based on the total number of female students. Finally, systematic random sampling technique was used to select 385 particiapnts [139 $(36.1 \%)$ from Jimma Institute of Technology, 98(25.45\%) from the Public Health and Medical Sciences, 52(13.5\%) from Social Science and Law, 38 $(9.8 \%)$ from Natural Science, 34, (8.8\%) from Agriculture and Veterinary Medicine and 24 (6.2) $\%$ from Business and Economics colleges].

Data were collected using a pre-tested questionnaire followed by open ended questions containing physical, verbal and nonverbal items. The self-administered questionnaire is inherently problematic as students may not give valid and reliable information. To minimize this problem, different strategies including collection of data by trained data collectors and giving clarification by the data collectors if something was unclear were used. Moreover, the objective of the study was clearly communicated to the study participants orally and in written form, and good rapport was also established in order to maximize the trustworthiness of the information students provided.

The questionnaire contained three sections. The first section contained items on demographic information. The second part consisted of items on physical, verbal and nonverbal sexual harassments in which participants responded on 'yes' or 'no' bases. Items on physical form of sexual harassment include, for example, purposely bumping or hurting someone, raping, attempting rape, and inappropriate touching. Inappropriate sexual comments about someone's body parts, telling sexual or dirty jokes and asking a favor for having sexual intercourse were some of the items 
included in the verbal form of sexual harassment. The nonverbal items include, among other things, displaying pictures of sexual nature through facebook and e-mail, inappropriate eye contact (twinkling) and inappropriate gesture that shows someone's sexual intention. Then, participants were categorized under experiencing physical, verbal, and nonverbal sexual harassments if they responded 'yes' to one or more of the items presented in each form of sexual harassment. Before the actual survey was conducted, a pre-test (pilot test) on 35 female students was done. Based on the pilot test result, some items were omitted and others modified. Cronbach's alpha reliability estimate for the harassment scale was computed to be 0.845 .

The last section, adopted from WHO, consisted of a standardized self-reported questionnaire (SRQ-20) for measuring psychological distress (11). The SRQ-20 has 20 questions that probed participants whether they had experienced specific symptom of psychological distress over one month period. They indicated their responses on 'yes' or 'no' basis. It has been adapted, validated and extensively used to measure psychological morbidity in Ethiopian settings. Participants who responded six or more items positively were regarded as having psychological distress as suggested by other studies (12-14).

Percentage was computed to determine the prevalence rate of various forms of sexual harassment and psychological distress. Chi-square test of independence was also conducted to determine how well different socio-demographic and various forms of sexual harassment were related to psychological distress as it is appropriate statistics to see the relationship between variables measured categorically. Finally, taking only variables that significantly related to psychological distress, multiple logistic regression analysis was conducted to check how well the significant variables predicted psychological distress. The reason for using logistic regression analysis was that the dependent variable was a categorical dichotomous variable $(>5$ distressed and $\leq 5$ not distressed). The two-tail test with $.05 \alpha$ level was used to check for statistical significance using Statistical Package for Social science (SPSS) software, version 20.0.

Ethical clearance was obtained from Jimma University ethical committee. In addition, permission letter was obtained from Department of Psychology. Initially, participants were told the objective of the research and then oral consent was obtained from the participants for their willingness to participate in the study. The participants also were told that the information they provide would be used solely for the research purpose. Confidentiality of participants was also assured throughout the research process.

\section{RESULT}

Of 385 female respondents, the majority of them $(256,66.5 \%)$ were found within the age range of 20-25. Almost all participants were single (380, $98.3 \%)$, lived in the campus $(381,98.9 \%)$ and were not substance users $(364,94.5 \%) .274$ (71.4\%) students received 100-499 Ethiopian Birr per month.

The self-reported prevalence rates of physical, verbal and nonverbal sexual harassments were $78.2 \%, 90.4 \%, 80.0 \%$, respectively. The prevalence rates of psychological distress among all female student participants and students who had experienced sexual harassment were $60.3 \%$ and $63.0 \%$, respectively, as measured by SRQ-20. (Table 1).

Table 1: The prevalence rates of physical, verbal, nonverbal harassments and psychological distress among Jimma University female students, May 2014

\begin{tabular}{lcc}
\hline Variables & YES* & NO $\dagger$ \\
\hline Physical harassment & $301(78.2 \%)$ & $84(21.8 \%)$ \\
Verbal harassment & $348(90.4 \%)$ & $37(9.6 \%)$ \\
Nonverbal assessment & $308(80.0 \%)$ & $77(20 \%)$ \\
Psychological distress & $232(60.3 \%)$ & $153(39 \%)$ \\
Psychological distress $\ddagger$ & $230(63.0 \%)$ & $135(36.7 \%)$
\end{tabular}

*Coded $1 \quad$ †Coded $0 \quad$ † Of experienced sexual harassment


The participants reported that nearly three-fourth of the various form of harassments were perpetrated by university students. One-fourth of the various forms of harassment were perpetrated by off campus boys (Table 2).

Table 2: Harassers on various types sexual harassment of female students in Jimma University, May 2014

\begin{tabular}{llcc}
\hline Harassers & Physical harassment & Verbal harassment & Non-verbal harassment \\
& \multicolumn{1}{c}{$\mathrm{N}(\%)$} & $\mathrm{N}(\%)$ & $\mathrm{N}(\%)$ \\
\hline University students & $286(67.6)$ & $345(63.7)$ & $302(71.6)$ \\
Off campus boys & $117(27.7)$ & $157(28.9)$ & $104(24.6)$ \\
University teachers & $15(3.5)$ & $36(6.6)$ & $16(3.8)$ \\
Total administrative staff & $5(1.2)$ & $4(0.7)$ & $0(0.0)$ \\
\hline
\end{tabular}

With respect to univariate analysis of the relationship between socio-demographic information and the various forms of harassment, physical sexual harassment had statistically significant association with college attendance $(\chi 2=8.02, \quad \mathrm{p}=0.00)$, substance use history $(\chi 2=6.199, \mathrm{p}=0.013)$ and monthly income (money received from parents or other sources on monthly bases) $(\chi 2=13.144, p=0.004)$, but not associated with level of year, marital status, residence and ages of students. Verbal sexual harassment $\left(\chi^{2}=\right.$ $11.46, \mathrm{p}=0.043)$ and nonverbal sexual harassment $(\chi 2=22.89, \quad \mathrm{p}=0.00)$ had also statistically significant relationship with college attendance but not related with age, level of year, marital status, residence, substance use history and monthly income (Table 3).
The socio-demographic variables that had statistically significant relationship with various forms of sexual harassments entered into the model to test how well they predicted the various forms of harassment. Consequently, the multivariable logistic regression analysis revealed that College of Public Health and Medicine female students were 3 times more likely to be physically harassed than those in College of Social Science and Law (Adjusted OR=3.075, 95\% CI=1.176, 8.043). Female students who earned 100-499 were 10 times more likely to be physically harassed than students who had no income (Adjusted OR= $10.228,95 \% \mathrm{CI}=2.891,36.193)$. But there was no significant difference in physical harassment among substance users and non-users. Students' college attendance did not predict verbal harassment and nonverbal harassment significantly in the final model (Table 4). 
Table 3: The association of socio-demographic variables with various forms of sexual harassments among female students in Jimma University, May 2014

\begin{tabular}{|c|c|c|c|c|}
\hline \multicolumn{5}{|c|}{ Sexual harassment } \\
\hline \multirow[t]{2}{*}{ Variables } & Yes & No & \multirow[t]{2}{*}{$\chi^{2}$} & \multirow[t]{2}{*}{$\mathrm{p}$} \\
\hline & $\mathrm{N}(\%)$ & $\mathrm{N}(\%)$ & & \\
\hline \multicolumn{5}{|c|}{ Physical Sexual harassment } \\
\hline \multicolumn{5}{|l|}{ College attended } \\
\hline Social science \& law & $45(11.6)$ & $7(1.8)$ & \multirow{6}{*}{8.02} & \multirow{6}{*}{$<0.001$} \\
\hline Natural science & $32(8.3)$ & $6(1.5)$ & & \\
\hline Public health and Medicine & $56(14.5)$ & $42(10.9)$ & & \\
\hline Institute of technology & $117(30.3)$ & $22(5.7)$ & & \\
\hline Business \& economics & $24(6.2)$ & - & & \\
\hline Agriculture & $27(7.0)$ & $27(7.0)$ & & \\
\hline \multicolumn{5}{|l|}{ Substance use history } \\
\hline Yes & $21(5.5)$ & - & \multirow[b]{2}{*}{6.199} & \multirow[b]{2}{*}{0.011} \\
\hline No & $280(72.7)$ & $84(21.8)$ & & \\
\hline \multicolumn{5}{|l|}{ Monthly income } \\
\hline No income & $4(1.0)$ & $1(0.3)$ & \multirow{4}{*}{13.144} & \multirow{4}{*}{0.004} \\
\hline$<100$ & $40(10.4)$ & $24(6.2)$ & & \\
\hline $100-499$ & $19(56.8)$ & $55(14.3)$ & & \\
\hline 500 and above & $38(9.8)$ & $4(1.0)$ & & \\
\hline \multicolumn{5}{|c|}{ Verbal Sexual harassment } \\
\hline Collages attended & & & \multirow{7}{*}{11.46} & \multirow{7}{*}{0.043} \\
\hline Social science \& law & $47(12.2)$ & $5(1.3)$ & & \\
\hline Natural science & $34(8.8)$ & $4(1.0)$ & & \\
\hline Public health and Medicine & $81(21.0)$ & $17(4.4)$ & & \\
\hline Institute of technology & $130(33.7)$ & $9(2.3)$ & & \\
\hline Business \& economics & $24(6.2)$ & - & & \\
\hline Agriculture & $32(8.3)$ & $2(0.5)$ & & \\
\hline \multicolumn{5}{|c|}{ Non-Verbal Sexual harassment } \\
\hline Social science \& law & $40(10.38)$ & $12((3.1)$ & \multirow{6}{*}{22.89} & \multirow{6}{*}{$<0.001$} \\
\hline Natural science & $34(8.8)$ & $4(1.03)$ & & \\
\hline Public health and Medicine & $65(16.9)$ & $33(8.6)$ & & \\
\hline Institute of technology & $119(30.9)$ & $20(5.2)$ & & \\
\hline Business \& economics & $24(6.2)$ & - & & \\
\hline Agriculture & $26(6.8)$ & $8(2.1)$ & & \\
\hline
\end{tabular}


Table 4: Adjusted odd ratio and significance level for predicting various forms of Harassment among female students in Jimma University, May, 2014

\begin{tabular}{|c|c|c|c|}
\hline Variables & Adjusted OR & 95.0\% C.I. & $\mathrm{P}$ \\
\hline \multicolumn{4}{|c|}{ Physical harassment } \\
\hline \multicolumn{4}{|l|}{ College attended } \\
\hline Collage of social science and law & 1.00 & & \\
\hline Collage of natural science & 0.675 & $0.19-2.385$ & 0.532 \\
\hline Collage of public health & 3.075 & $1.176-8.043$ & 0.001 \\
\hline Institute of technology & 1.074 & $0.417-2.769$ & 0.959 \\
\hline Collage of business and economics & 0.000 & 0.000 & 0.988 \\
\hline Collage of agriculture & 1.531 & $0.470-4.986$ & 0.467 \\
\hline \multicolumn{4}{|l|}{ Monthly income } \\
\hline No income & 1.00 & & \\
\hline$<100$ & 5.604 & $0.434-72.350$ & 0.484 \\
\hline $100-499$ & 10.228 & $2.891-36.193$ & 0.687 \\
\hline Above 500 & 2.682 & $0.864-8.319$ & 0.220 \\
\hline \multicolumn{4}{|l|}{ Substance use history } \\
\hline No & 1.00 & & \\
\hline Yes & 0.00 & 0.00 & 0.998 \\
\hline \multicolumn{4}{|c|}{ Verbal harassment } \\
\hline \multicolumn{4}{|l|}{ College attended } \\
\hline Collage of social science and law & 1.00 & & \\
\hline Collage of natural science & 1.106 & $0.276-4.426$ & 0.887 \\
\hline Collage of public health & 1.973 & $0.684-5.694$ & 0.209 \\
\hline Institute of technology & 0.651 & $0.208-2.041$ & 0.461 \\
\hline Collage of business \&economics & 0.000 & 0.000 & 0.998 \\
\hline Collage of agriculture & 0.587 & $107-3.217$ & 0.540 \\
\hline \multicolumn{4}{|c|}{ Nonverbal harassment } \\
\hline College attended & & & \\
\hline Collage of social science \&law & 1.00 & & \\
\hline Collage of natural science & 0.392 & $116-1.329$ & 0.113 \\
\hline Collage of public health & 1.692 & $0.784-3.652$ & 0.180 \\
\hline Institute of technology & 0.560 & $252-1.247$ & 0.156 \\
\hline Collage of business and economics & 0.000 & 0.000 & 0.998 \\
\hline Collage of agriculture & 1.026 & $0.369-2.849$ & 0.961 \\
\hline
\end{tabular}

With respect to the relationship of the various forms of harassment and psychological distress, the univariate analysis indicated psychological distress had a statistically significant association with physical $(\mathrm{p}<0.001)$, verbal $(\mathrm{p}<0.001)$, nonverbal sexual harassment $(\mathrm{p}<0.001)$ and college attended $(\mathrm{p}<0.001)$ but not with other socio demographic characters like age, level of year, marital status, residence substance use history and monthly income of respondents (Table $5)$. 
Table 5: The association various forms of sexual harassment and students' college attendance with psychological distress among female students in Jimma University, May 2014

\begin{tabular}{|c|c|c|c|c|}
\hline \multirow[t]{2}{*}{ Variables } & \multicolumn{2}{|c|}{ Psychological distress } & \multirow[t]{2}{*}{$\chi^{2}$} & \multirow[t]{2}{*}{$\mathrm{p}$} \\
\hline & Yes & No & & \\
\hline \multicolumn{5}{|l|}{ Physical harassment } \\
\hline Yes & $215(55.8)$ & $86(22.3)$ & 71.8 & $<0.001$ \\
\hline No & $17(3.1)$ & $67(17.4)$ & & \\
\hline \multicolumn{5}{|l|}{ Verbal harassment } \\
\hline Yes & 227(58.9) & $121(31.4)$ & 37.3 & $<0.001$ \\
\hline No & $5(1.29)$ & $32(8.3)$ & & \\
\hline \multicolumn{5}{|l|}{ Nonverbal harassment } \\
\hline Yes & $224(58.1)$ & $84(21.8)$ & 99.9 & $<0.001$ \\
\hline No & $8(2.1)$ & 69(17.9) & & \\
\hline \multicolumn{5}{|l|}{ Collages } \\
\hline Social science \& law & $33(8.6 \%)$ & $19(4.9 \%)$ & 42.34 & $<0.001$ \\
\hline Natural \& computational science & $26(6.8 \%)$ & $12(3.1 \%)$ & & \\
\hline Public health & $36(9.4 \%)$ & $62(16.1 \%)$ & & \\
\hline Institute of technology & $93(24.2 \%)$ & $46(11.9 \%)$ & & \\
\hline Business \& economics & $24(6.2 \%)$ & - & & \\
\hline Agriculture & $20(5.2 \%)$ & $14(3.6 \%)$ & & \\
\hline
\end{tabular}

Table 6: Adjusted odd ratio and significance level for predicting psychological distress among female students in Jimma University, May, 2014

\begin{tabular}{lcccc}
\hline Variables & SRQ $>5$ & Adjusted OR & 95\% C.I. & P \\
\hline N $(\%)$ & & & \\
\hline Physical sexual harassment & & & & \\
$\quad$ Yes & $215(92.7)$ & 3.95 & $1.979-7.884$ & $<0.001$ \\
$\quad$ No & $17(7.3)$ & 1.00 & & \\
Verbal sexual harassment & $227(97.8)$ & 1.694 & $.513-5.595$ & 0.387 \\
$\quad$ Yes & $5(2.2)$ & 1.00 & & \\
$\quad$ No & $224(96.6)$ & 12.099 & $5.190-28.205$ & $<0.0001$ \\
Nonverbal sexual harassment & $8(3.4)$ & 1.00 & & \\
Yes & & & & \\
No & $33(14.2)$ & 1.00 & & \\
College & $26(11.2)$ & 1.069 & $0.380-3.010$ & 0.899 \\
Social Science and Law & $36(15.5)$ & 2.400 & $1.033-5.578$ & 0.042 \\
Natural science & $93(40.1)$ & 1.100 & $0.496-2.443$ & 0.814 \\
Public Health and Medicine & $24(10.3)$ & 0.000 & 0.000 & 0.998 \\
Institute of Technology & $20(8.6)$ & 1.204 & $0.418-3.472$ & 0.731 \\
Business and Economics & & &
\end{tabular}

The various forms of sexual harassment and college attended that had statistically significant relationship to psychological distress entered into the model to test how well they predicted psychological distress. Accordingly, the multivariate logistic regression analysis indicated that students who were physically (adjusted OR $=3.950,95 \% \mathrm{CI}=1.979,7.884)$, nonverbally (adjusted OR $=12.099,95 \% \mathrm{CI}=5.190,28.205)$ harassed and attended Public Health and Medicine College (adjusted OR $=2.400,95 \% \mathrm{CI}=1.033$ 75.578) were 4, 12 and 2 times more likely to 
experience psychological distress relative to female students who were not physically, nonverbally harassed and attended College of Social Science and Law students, respectively, adjusted for all other variables. Verbal harassment did not predict significantly psychological distress in the final model (Table 6).

Evidence on various forms of sexual harassment from the open-ended questions: Female students reported that some university students and off campus people verbally harass them with shameful sexual words. They also added that few university teachers reduced grades and also gave them ' $F$ ' grades when they were not agreed for sexual intercourse. In this regard, one respondent reported: "My teacher asked me for sexual intercourse but I was not okay. As a result, he gave me ' $F$ ' grade in his course'. The other respondent also added: "My teacher asked me to be his girlfriend and I refused. Then, he asks me questions in his period always. If I couldn't answer the questions, he said me 'stupid' usually".

They also reported some forms of nonverbal harassment including disturbing them while they read in library, sending badly written messages through their phone, e-mail, and face books address and distributing false rumors. One respondent also added: "Someone asked me to be his girlfriend but I refused. Immediately, he told my best friends that as I am living with HIV/AIDS'. Physical form of violence was also common. They reported that beating female students was a common phenomenon while they were off campus.

\section{DISCUSSION}

Previous studies used the general notion of sexual harassment giving little emphasis to its various forms. In this study, however, the prevalence rates of the various forms of sexual harassment were assessed among Jimma University female students. The findings indicated that the prevalence rates of the various forms of sexual harassment were higher relative to previous findings $(6,7,8)$. The reason for the inconsistent findings might reside on focusing on the general notion of sexual harassment as opposed to verbal, physical and non verbal sexual harassments in previous studies. Such practices of conceiving and collapsing the three types of sexual harassment as one construct seemed to dilute the true prevalence rates and generate a low prevalence rate. Similarly, differences on definitions of sexual harassment, type of items used and scoring procedure in this study and previous studies could also have contributed to the different prevalence rates.

On the other hand, verbal harassment was the most prevalent sexual harassment as consistent with other studies $(4,16)$. Different explanations could be given for the highest prevalence of verbal harassment. It seems that victims of verbal harassment rarely reported the incidences to legal bodies due to feelings of shame, lack of awareness on what to do and where to go (20). As a result, harassers are usually left unpunished and then they would be reinforced to harass other people too in the future. In addition, according to social learning theory, people learn new behavior from observing others. It is common to hear male students and off campus boys throw sexual words against female students. As a result, other students and off campus boys may mimic this behavior and display verbal harassment against female students (21).

Similarly, the nonverbal form of sexual harassment was the second most prevalent. It is not surprising to see high prevalence rate of nonverbal form of harassment when people have the means and easy access to technology nowadays which eases the exchange of information efficiently and rapidly. The expansion and innovation of technology like e-mail, facebook and mobile phone encourage peoples to communicate sexual messages or pictures to people around; and thus could contribute to the consistent increment of nonverbal forms of sexual harassment (15).

Comparatively speaking, physical form of sexual harassment was the least prevalent. The reason for this might be that people have no tolerance for physical harassment and may fight back the harasser or report the incidence to legal agencies. As a result, fearing the consequences, perpetrators may not be engaged in physical harassments as frequently as they exercise verbal and nonverbal harassments $(20,21)$.

The prevalence rate of psychological distress among Jimma University female students was high in consistent with the report of Haramya University (17), while it contradicted with the findings of Abakaliki, South Nigeria Ebonyi State 
University (10). This difference could be attributed to difference in socio-cultural setting between the study populations.

In this study, the probability of having psychological distress among female students who were physically and nonverbally harassed was higher. This could be due to the effect of psychosomatic impairment including symptoms of depression, anxiety, and ill-health accompanying harassments. It is well documented that psychological distress not only interferes with females' rights and deteriorate their psychological health, but also affects negatively their scholastic achievement and makes them less productive $(10,18,19)$. However, verbal harassment failed to predict psychological distress significantly as it might be that female students may not take it seriously to the extent of damaging their psychological makeup.

In this study, female students reported that they were harassed by university students followed by off campus boys and rarely by their teachers and administrative staffs. This finding is consistent with the study on US college students where the most common harassers were students (4). Since the vast majority of campus population is male students, it may not be surprising that they were the commonest harassers and the finding may suggest a student culture that accepts or at least seems to tolerate this type of behavior. The second most common harassers were off campus boys that could signify the environment outside campus was not safe for female students. Teachers were the third most common harassers in which it would be traumatic as the harassers were in a position or power that can foster learning helplessness $(4,19)$.

In conclusion, this study indicated that the overall prevalence rates of verbal, nonverbal and physical sexual harassments among Jimma University female students were very high and the most common harassers were university students and off campus boys; and rarely university teachers and administrative staffs. Students who were physically and nonverbally harassed were more likely to experience psychological distress relative to female students who were not physically and nonverbally harassed.

These findings have important implications for the university officials and policy makers. Universities should be free form any form of harassment, and thus, Jimma University officials should create harassment-free environments to smoothly conduct the teaching learning process so that females' academic performance and graduation rate increases. Otherwise, as a result of psychological distress that accompanies harassments, female students tend to dropout and the government's effort for bringing the gender parity in university education would be at a stake.

Particularly, Jimma University in collaboration with the Gender Office must formulate a workable policy against the various forms of female sexual harassment, and ensure its implementation. In addition, creating awareness among the university community on the negative impacts of various forms of sexual harassments on female students, empowering and building the capacity of female students on their right and how to deal with sexual harassments, taking strong action against harassers are some of the strategies that could minimize the problem. Moreover, the University should work in collaboration with the community, the police and Keble administrators at large to fight against female sexual harassments since the problem was also rampant outside the campus.

Since psychological distress was higher among female university students, strengthening counseling service for female students and establishing referral linkage with psychiatric clinic of Jimma Hospital are strongly recommended. To get a nationwide picture, further study covering other higher institutions in the country is a necessity. Moreover, additional study including academic stress, social support, threats due to high expectations from parents and teachers is also needed to get complete pictures of variables affecting psychological distress.

\section{ACKNOWLEDGEMENTS}

We would like to express our deepest gratitude to Jimma University for financing the research. We would also like to thank Dr. Aemero Abateneh for his professional support and encouragement throughout the research process. Our gratitude also goes to Jimma University female students for their consent to participate in the study and filling out the questionnaire. 


\section{REFERENCES}

1. American Association of University Women Educational Foundation. Hostile Hallway Survey on sexual harassment in America's schools. Washington, DC; 2001.

2. World Health Organization (WHO). Violence against women: Aphorize health issue, Geneva, 1997.

3. American Association of University women Educational Foundation. Hostile Hallway Survey on sexual harassment in America's schools. Washington, DC; 2002.

4. Hill C, Silva E. Drawing the line: Sexual harassment on campus. Washington, DC: American Association of University Women Educational Foundation; 2005.

5. Mersha Y, Bishaw A, Tegegne F. Factors Affecting Female Students' Academic Achievement at Bahir Dar University. Journal of International Cooperation in Education, 2013; 15(3):135-148.

6. Seblework T, Ahimed A, Deyasa N. Assessment of Sexual Coercion among Addis Ababa University Female Students, Addis Ababa, Ethiopia; 2004 Available at etd.aau.edu.et/dspace/bitstream/123456789/.../ Seblework\%20Tadess (accessed on june,2014).

7. Kassahun T. Sexual harassment in the case of Jimma University, Ethiopia; 2009. Available at

etd.aau.edu.et/dspace/bitstream/123456789/.../ Tibebe\%20 Kassahun (accessed on june,2014)

8. Demise A, Shinebaumm R, Melesse K. The problems of female students at Jimma University, with some suggested solutions. Ethiopian Journal of Health Development 2002; 16 (3):257-266.

9. Garcia-Moreno C. Violence against women. Gender and Health Equity working paper series No 99.15. Cambridge: Harvard Center for population and development studies, Harvard School of Public Health; 1999.

10. Ogbonnaya L, Ogbonnaya C, Emma E, Echiegu N. Prevalence of sexual harassment of female students in Ebonyi State University Abakaliki, South East Nigeria. Journal of community medicine and primary health care, 2011; 23:1-2.
11. World Health Organization, Division of Mental Health. A user's guide to the SelfReporting Questionnaire (SRQ). Geneva: World Health Organization; 1994.

12. Kebede D, Alem A, Rashid E. The prevalence and socio-demographic correlates of mental distress in Addis Ababa, Ethiopia. Acta Psychiatr Scand Suppl, 1999; 397: 5-10.

13. Esayas S. Mekonen E. Correlates of mental distress in Jimma town, Ethiopia, Ethiopian journal of health science, 2003;13(1):39-49.

14. Kurtman Kortmann F. Psychiatric case finding in Ethiopia: shortcomings of the Self Reporting Questionnaire. Cult Med Psychiatry, 1990; 14(3): 381-391.

15. Jewkesm, R, Abrahams, N., The epidemiology of rape and sexual coercion in South Africa: an overview. Social Science and Medicine, 2008.

16. Suhaila O, Rampal K. Prevalence of Sexual Harassment and its Associated Factors among Registered Nurses Working in Government Hospitals in Melaka State, Malaysia. Med J Malaysia, 2012; 67(5):506-17.

17. Galmessa A. Assessment of prevalence, determinants and effects of mental distress among Alemaya university students, Addis Ababa, Ethiopia.2005.

18. Roeser W, Eccles S, Freedman-Doan C. Academic functioning and mental health in adolescence: Patterns, progressions, and routes from childhood. Journal of Adolescent Research, 1999; 14:135-174.

19. Marisela H, Lilia C, Joyce $\mathrm{P}$, \&, Cynthia T. Sex and Power in the Academy: Modeling Sexual Harassment in the Lives of College Women in Michigan University. Journal of the Society for Personality and Social Psychology, 2006; 47:272-250.

20. Gorfu M, Demise A. Sexual Violence against Schoolgirls in Jimma zone: Prevalence, Pattern and Consequences. Ethiopian Journal of Education and Science, 2007; 2(2):11-37.

21. Abebe K, Sintayehu M. Types, Magnitude, Predictors and Controlling Mechanisms of Aggression in Secondary Schools of Jimma Zone. Ethiopian Journal of Education and Science, 2007; 2(2):39-61. 